whether the crop is safe for the environment and human consumption. If the assessment proves positive, blanket approval would probably be given for the crop to be grown commercially in all COMESA countries. National governments would retain the power to decide whether or not to proceed.

Risk assessments are currently left to individual countries, but this requires scientific expertise, money and a well-established regulatory system. That combination is rare in Africa, and only four countries - Malawi, Zambia, Zimbabwe and Kenya - have passed laws specifically to govern GM organisms. This helps to explain why there are so few GM crops grown commercially across Africa. Even field trials of GM crops are scarce, although tests of a banana engineered to resist bacterial disease will begin in Uganda this week (see Nature doi:10.1038/news.2010.509; 2010).

Under the COMESA plan, the African nations are consulting on a biosafety road map to guide the development of national regulations on transgenic organisms, and on regimes and mechanisms for monitoring and inspection. A communication strategy to provide countries with the latest scientific information on GM organisms is also under discussion.

The consultation is expected to continue until March, with a decision coming from the relevant ministers soon after. If agreed, the proposals will help many more African nations to explore agricultural biotechnology should they wish to, and perhaps to profit from the increased food security that the technology has the potential to provide. By working together, nations will also benefit from greater access to the experience of commercial issues relating to GM technology that is currently the preserve of just a few African countries.

For their efforts so far, these nations should be applauded, as should the African scientists who have managed to get their voices heard in a difficult and contentious debate. The moves signal a shift towards evidence-based assessments of technologies that could hold much promise for the continent.

African countries have been wise to draw from the speed and enthusiasm with which nations such as Brazil have exploited GM technology, rather than the confused and fearful stance of European countries such as France. The few GM crop initiatives across Africa are already dispelling some myths peddled by the anti-GM lobby, such as the image of poor African farmers being exploited by profiteering multinational companies. In fact, many of the existing projects involving GM organisms in Africa are public-private partnerships through which companies donate their best technologies royalty-free.

It is by no means certain that the COMESA proposals will get through the consultation unscathed. A key sticking point is concern in some countries that regional guidelines would usurp national sovereignty. And although Zambia is the only country in the bloc to take an explicit anti-GM stance, others are pushing for tougher rules that could restrict the adoption of the technology.

African countries should not let ideological opposition to GM technology cloud the admirably clear view that they have taken on the issue so far. Food and water shortages that already ravage the continent will only get worse, and GM technology offers a promising way to tackle poverty and poor agricultural productivity. The question is not whether countries there should adopt GM crops, but how quickly.

\section{Garage biology}

\section{Amateur scientists who experiment at home should be welcomed by the professionals.}

$\mathrm{F}$ or the past two years, a group of molecular-biology enthusiasts has met regularly in Cambridge, Massachusetts, to discuss science. Their conservation is not entirely theoretical: they swap stories about the experiments they perform in rudimentary labs built in their kitchens, basements and garages. These meetings are not unique: similar gatherings are cropping up across the United States and Europe, as amateur scientists get together to compare protocols and results from experiments they design and conduct at home.

Do-it-yourself biologists emerged into the spotlight after the first meeting, in a Cambridge pub, in 2008. Their exploits have since earned them a moniker fit for the headlines of the twenty-first century: biohackers (see page 650). Media coverage has taken its toll on the public's perception of 'DIYbio'. Stories in the press are often peppered with sweeping claims of the monumental advances to be made by unleashing the talents of the public at large on important biological questions. Equally common are breathless warnings that a bioterrorist is busy crafting the next plague in a garage, safe from the watchful eye of the authorities.

Neither image rings true. Most biohackers are hobbyists who delight in crafting their own equipment and who tackle projects no more sophisticated than those found in an advanced high-school biology lab. This is not to belittle their achievements - the most basic lab experiments can be a challenge without the institutional infrastructure professional scientists take for granted. And it is not necessarily the sophistication of the techniques, but the questions to which they are applied, that makes for compelling science. Nevertheless, the high financial and educational barriers to cutting-edge molecular biology means that garage labs are unlikely to solve the world's energy or health problems any time soon. As for that imagined bioterrorist, US experts at the FBI's Weapons of Mass Destruction Directorate have investigated and found no sign of a biohacker who intends harm.

Nevertheless, the bureau is wise to plan ahead. The FBI has embarked on a laudable and proactive programme to establish ties with the amateur biology community. FBI agents attend DIYbio meetings and invite DIYbio leaders to conferences on bioterrorism. This has yielded some practical plans, such as notifying police and fire stations about local garage labs, to avoid unpleasant surprises or false alarms in the event of an emergency. But some in the biohacking community worry that the constant focus on bioterrorism has taken attention and resources away from a more pressing issue: basic biosafety. How should a biohacker dispose of unwanted genetically engineered bacteria? How does an amateur biologist avoid exposure to fumes from the chemicals used to isolate and manipulate DNA? What is a safe bacterium for a hobbyist to play with?

These are questions that crop up daily in a garage lab, and amateur biologists have struggled to find answers. Although institutions such as the US National Institutes of Health (NIH) and the Centers for Disease Control and Prevention have established biosafety guidelines, these are aimed at institutional biosafety officers with training in the field. Laden with jargon and focused on advanced work with dangerous chemicals and pathogens that hobbyists are unlikely to encounter, the guidelines are little help in the garage. Does this knowledge gap provide an opportunity for professional scientists to engage and support the DIYbio community? Some researchers argue it does, with professionals helping garage biologists craft safety guidelines and standards that could be understood by the enthusiast. Biohackers could also be brought onto biosafety committees at their local university or medical centre. These committees are required by the NIH to include at least one member who is not a professional scientist. Serving on a such committee would expose the hobbyist to the regulations and protocols that research institutions use to protect workers and the environment.

Biohackers are an example of the growing 'citizen science' movement, in which the public takes an active role in scientific experiments. Citizen science can help stimulate public support for science, and can introduce fresh ideas from novel disciplines. Science is a professional business but it would be a shame if the only interested knock on the hobbyists' doors came from those in law enforcement. 